\title{
Evaluation of Addition of Carbon Nano Materials Over Properties of an Elastomeric Matrix
}

\author{
BEATRIZ ADRIANA SALAZAR-CRUZ ${ }^{1}$, JOSÉ LUIS RIVERA-ARMENTA ${ }^{1 *}$, \\ CYNTHIA GRACIELA FLORES-HERNÁNDEZ ${ }^{2}$, JUVENTINO LÓPEZ-BARROSO ${ }^{2}$, \\ JORGE ESTRADA-MARTÍNEZ ${ }^{3}$, MARÍA YOLANDA CHÁVEZ-CINCO ${ }^{1}$ \\ ${ }^{1}$ Tecnológico Nacional de México/Instituto Tecnológico de Ciudad Madero, Petrochemical Research Center, Altamira, \\ Tamaulipas, 89600, México \\ ${ }^{2}$ Tecnológico Nacional de México/Instituto Tecnológico de Querétaro, Santiago de Queretaro, Querétaro, 76000, México \\ ${ }^{3}$ Tecnológico Nacional de México/Instittuto Tecnológico de Altamira, Altamira, Tamaulipas, 89600 México
}

\begin{abstract}
In the present work, the effect of the addition of different types of carbon nano structures on the mechanical, thermomechanical and thermal properties of a radial structure of styrene-butadienestyrene $\left(S B S_{R}\right)$ copolymer matrix is reported. Different carbon nanostructures were used as nano-reinforcements: expanded graphite $(X G)$, graphene oxide $(G O)$, reduced graphene oxide $(R G O)$ and exfoliated graphene (EG). These carbon structures present various functional groups, such as carbonyl, epoxy, and others, which are the responsible for the interaction between the polymer matrix and the nano particles. The compatibility induced between the nanomaterials and the elastomeric matrix favors the stable dispersion of the nanocomposites during their obtention process. For instance, the addition of GO increased in 10 and 16\% the tensile strength and storage modulus of the nanocomposites. The fracture surface patterns in the nanocomposites after the tensile test was observed by scanning electron microscopy. Also, the dynamic mechanical analysis (DMA) and thermal characterization showed differences in the viscoelastic behavior of the reinforced nanocomposites with different carbon nanomaterials.
\end{abstract}

Keywords: carbon nanomaterials, thermal properties, styrene-butadiene-styrene

\section{Introduction}

The development of high-performance polymer composites has become a challenge for materials researchers, who work on obtaining multifunctional materials for various purposes $[1,2]$. Composite materials of polymeric matrices exhibit improvements in their mechanical, thermal and chemical properties when modified with reinforcement materials, due to the fact that their interfaces are reenriched by the synergistic effect between the matrix and the nanostructure; however a typical micro reinforcement usually creates better interfaces and, consequently, produces notable improvements in mechanical properties, as well as in chemical and environmental resistance [1-3]. On the other hand, some of the most important challenges on this matter, such as easing the nano-reinforcement dispersion or impregnation of fibers and nanoparticles, as well as dealing with the high volume of microreinforcement particles, have not been yet solved entirely [3]. The primary function of the polymeric matrix in a composite is to provide elasticity, flexibility, strength, as well as other unique physical properties. There is a wide diversity of polymeric matrices like elastomers, thermoplastics, and epoxies with different stereochemical configurations like linear, radial, and multi-radial block copolymers, hydro, and aerogels [1]. Since the typical poor reinforcement-matrix compatibility implies deficient mechanical properties, some strategies have been explored in order to overcome this problem on the composite preparation, such as chemical functionalization or using coupling agents [4].

Carbon allotropes are classified according to the type of their bonds, for instance in $\mathrm{sp}^{2}$ hybridization, graphite, graphene and carbon nanotubes [2]. Graphene is recognized as the hardest material in the world, with a Young's modulus value of $1 \mathrm{TPa}$ and a breaking strength of $130 \mathrm{GPa}$, according to several references [5-8].

\footnotetext{
*email: jlriveraarmenta@itcm.edu.mx
} 
Graphene has excellent mechanical, thermal, and electrical properties. This carbon nanomaterial is one of the most used and preferable reinforcers, standing out over nano clays like montmorillonite sodium (Na-MMT), or layered double hydroxide (LDH), because of its high surface area, as well as its notable thermal and electrical conductivity; for these reasons, nowadays, graphene is considered as the best nano filler for polymeric matrices [9-11]. However, pristine graphene is not compatible with organic polymers and does not form homogeneous components $[9,11]$. In order to overcome these shortcomings, carbon-based nanoreinforcers, such as carbon black, exfoliated graphite, carbon nanotubes (CNT), graphene nano sheets, and functionalized carbon nanotubes (FCNT) have been used for the preparation of polymer nanocomposites $[1,812,13]$.

On the other hand, there are many studies on expanded and exfoliated graphite composites based on a vast range of polymers including epoxy, poly methyl-methacrylate (PMMA), polypropylene (PP), linear low-density polyethylene (LLDPE), high-density polyethylene (HDPE), polystyrene (PS), Nylon, polyaniline, phenylethynyl-terminated polyimide, and silicone rubber [1, 6, 14]. Additionally, several mechanisms have been proposed to incorporate the polymer into the core of multilayer materials [7]. For instance, the method of intercalation by in situ polymerization, where graphene or modified graphene is first swollen within the monomer's liquid, then a suitable initiator is diffused, and the polymerization is initiated by heat or by radiation. Besides, the solution intercalation method is based on the selection of a suitable solvent in which the polymer is solubilized, and the layers of graphene or modified graphene are swollen by the polymer chains. The main advantage of this method is that it allows the synthesis of intercalated nanocomposites based on polymers with low or even no polarity. Then, the polymer is adsorbed on the delaminated sheets, and when the solvent evaporates, the sheets are reassembled, placing the polymer in the sandwich to form the nanocomposites. In the melt intercalation method, no solvent is required, and graphite or modified graphene is mixed with the polymer matrix in a molten state. In this intercalation technique, the copolymer is mixed mechanically with graphite or modified graphene at elevated temperatures [1]. The graphene/polymer composite is mostly prepared using solvent mixing and in situ polymerization [7].

In this work, graphene derivatives were added into the elastomeric matrix through the molten mixing method, evaluating the effect of the chemical structure of the maxtrix (linear and radial) on the final properties. The effect of carbon nanoparticles on the mechanical, thermomechanical, and thermal properties of the elastomeric matrix were also studied.

\section{Materials and methods}

\subsection{Materials}

The carbon nanomaterials used in the present research were expanded graphite (XG), graphene oxide (GO), reduced graphene oxide (RGO), and exfoliated graphite (EG), which were obtained by synthesis methodologies previously published [3, 15-19]. The elastomeric matrix, a styrene-butadiene-styrene copolymer with radial structure $\left(\mathrm{SBS}_{\mathrm{R}}\right)$ with $30 \%$ of total styrene content and a viscosity of $28 \mathrm{cSt}$ in Toluene, was provided by Dynasol Elastomeros, (Altamira, Tamaulipas, Mexico).

\subsection{Composites preparation}

The nanocomposites were prepared by adding each nanomaterial into the polymer matrix at $0.01 \mathrm{wt}$. $\%$ and 0.1 wt. $\%$. Polymer and nanomaterials were melt-mixed by using a Brabender PL2000 torque rheometer (Plasti-corder). The mixing was carried out at $150^{\circ} \mathrm{C}$ and $50 \mathrm{rpm}$ for $15 \mathrm{~min}$. After that, the materials were compress-molded in a DAKE press, at $160^{\circ} \mathrm{C}$ and $14 \mathrm{kN}$ for obtaining $3.17 \mathrm{~mm}$-thick plates, from where samples for dynamic mechanical analysis and mechanical test were cut according to the description in subsequent sections.

\subsection{Composites characterization}

Scanning electron microscope (SEM)

The fracture micrographs of scanning electron microscopy (SEM) were obtained using HITACHI 
TM-1000 equipment (Hitachi, Tokyo, Japan) through backscattered electrons in a low vacuum at $15 \mathrm{kV}$. Samples with $\mathrm{N}_{2}$ were mounted on metal stubs and vacuum-coated with gold using a sputter coater (DENTON VACUUM Desk V HP), with a voltage operation of $20 \mathrm{kV}$.

\subsubsection{Mechanical testing}

The stress-strain curves were obtained using dog-bone shaped specimens in an Instron 3384 universal machine, with a crosshead rate of $5 \mathrm{~mm} / \mathrm{min}$ and a load cell of $10 \mathrm{kN}$, according to ASTM D638, with 5 replicas.

\subsubsection{Thermogravimetric Analysis (TGA)}

The thermal stability of the composites was evaluated by means a TA Instruments STD Q600 thermogravimetric analyzer under a nitrogen atmosphere with a flow of $100 \mathrm{~mL} / \mathrm{min}$, in a temperature range of 30 to $700^{\circ} \mathrm{C}$. The heating rate was $10^{\circ} \mathrm{C} / \mathrm{min}$, and the sample weight was $10 \mathrm{mg}$ approximately.

\subsubsection{Dynamic mechanical tests (DMA)}

The dynamic mechanical analysis (DMA) was carried out in a TA-Instruments model Q800 using a dual cantilever clamp, in multifrequency mode with an amplitude of $20 \mathrm{~mm}$ and frequency $1 \mathrm{~Hz}$, over the temperature range of -85 to $150^{\circ} \mathrm{C}$. The heating rate was $5^{\circ} \mathrm{C} / \mathrm{min}$. The sample size was $20^{*} 14^{*} 3$ $\mathrm{mm}^{3}$, and it was carried out in duplicate (the geometry was based on ASTM D4065).

\subsubsection{X-ray diffractometer (XRD)}

For X-ray diffraction analysis, thin films of nanocomposites were prepared, and their diffraction patterns were collected between 1 to $40^{\circ}$, using step- scanning mode of 0.016 grades $(2 \theta)$ and $60 \mathrm{~s}$ counting time at each step with a Lynxeye detector on PANalytical XPert'PRO diffractometer equipped with an $\mathrm{X}^{\prime} \mathrm{C}$ elerator detector and $\mathrm{CuK} \alpha$ radiation.

\section{Results and discussions}

\subsection{Mechanical properties}

The results obtained from the uniaxial tensile testing of the composites samples are shown in Table 1. As can be observed, the tensile strength (TS) of $\mathrm{SBS}_{\mathrm{R}}$ matrix and nanocomposites decrease compared with $\mathrm{SBS}_{\mathrm{R}}$ pristine.

The addition of 2D nano materials generated changes in the tensile strength (TS) of the nanocomposites $\mathrm{SBS}_{\mathrm{R}}-\mathrm{GO} 0.01 \mathrm{wt}$ \%, and $\mathrm{SBS}_{\mathrm{R}}-\mathrm{XG} 0.01 \mathrm{wt}$ \%, which exhibited increments of $16 \%$ and $2 \%$ in this property, respectively. The 2D carbon nanomaterials used as reinforcements have similar $2 \mathrm{D}$ structures to the pristine graphene, which outstanding properties are attributed to the high stability of the lattice built by the $\mathrm{sp}^{2}$ bonds [20]. The functional groups created during the synthesis, for example, in $\mathrm{GO}$ and $\mathrm{XG}$, disrupt the $\mathrm{sp}^{2}$ lattice and, consequently, the mechanical properties are impacted. In the nanocomposites, the remainder spy lattice present in GO is enough to use it as reinforcement, and it is responsible for improving the mechanical properties. Also, the functional groups present in these materials $(\mathrm{OH}, \mathrm{COOH}, \mathrm{C}=\mathrm{O})$ offer an advantage in terms of compatibility and dispersion compared to that of the pristine graphene, whose poor capability to form stable solutions prevents the formation of stable and homogenous dispersions and, therefore, restricts its application in the field of nanocomposite technology $[4,11,21]$.

Tan et al. reported the improvement of the mechanical properties of SBS nanocomposites by GO. They reported up to $24.2 \%$ improvements on the TS in the $\mathrm{SBS}_{\mathrm{R}}$ polymeric matrix reinforced with 3 wt. \% of functionalized graphene (f-G) [5]. According to those results, $\mathrm{f}-\mathrm{G}$ improved the TS and the elongation at break. In our case, $\mathrm{SBS}_{\mathrm{R}}-\mathrm{GO} 0.01 \mathrm{wt} . \%$ and $\mathrm{SBS}_{\mathrm{R}}-\mathrm{XG} 0.01 \mathrm{wt}$. \% match that behavior, evidencing an increase in both parameters.

As can be inferred from the results of the nanocomposites reinforced with $0.1 \%$, increasing the reinforcer load sacrifices the stiffness of the composites, but results in a tougher and more elastic 
behavior, as shown in Table 1.

Table 1. Mechanical properties of the $\mathrm{SBS}_{\mathrm{R}}$, and 2D nanocomposites

\begin{tabular}{|c|c|c|c|c|c|c|c|}
\hline Sample & wt. \% & $\begin{array}{c}\text { Modulus at } \\
300 \% \mathrm{MPa}\end{array}$ & $\begin{array}{c}\text { Std deviation, } \\
\mathrm{MPa}\end{array}$ & Strain $\%$ & $\begin{array}{c}\text { Std deviation, } \\
\%\end{array}$ & $\begin{array}{c}\text { Tensile } \\
\text { strength } \\
\mathrm{MPa}\end{array}$ & $\begin{array}{c}\text { Std deviation, } \\
\mathrm{MPa}\end{array}$ \\
\hline SBSR & 0 & 5.27 & 0.23 & 348.48 & 11.9 & 5.58 & 0.43 \\
\hline SBSR -GO & 0.01 & 3.09 & 0.21 & 498.19 & 18.7 & 6.1 & 0.46 \\
\hline & 0.1 & 5.22 & 0.22 & 356.07 & 12.6 & 5.36 & 0.41 \\
\hline SBS $_{\mathrm{R}-\mathrm{RGO}}$ & 0.01 & 4.34 & 0.24 & 319.80 & 11.7 & 4.9 & 0.32 \\
\hline & 0.1 & 5.28 & 0.29 & 316.37 & 10.8 & 5.2 & 0.39 \\
\hline SBSR -EG & 0.01 & 3.32 & 0.19 & 416.6 & 13.0 & 4.27 & 0.36 \\
\hline SBS $_{\mathrm{R}}-\mathrm{XG}$ & 0.01 & 3.09 & 0.17 & 583.72 & 20.7 & 5.71 & 0.27 \\
\hline
\end{tabular}

\subsection{Fracture characterization}

Figure 1 presents the SEM micrographs of the fractured surfaces of the elastomeric matrix, as well as those of the nanocomposites. Figure 1-a shows the fracture surface of $\mathrm{SBS}_{\mathrm{R}}$ elastomer. The addition of modified graphene particles in an elastomeric matrix present micrometrical dimension and a flake form that did not show any exfoliation [12].

The Figures $1 \mathrm{~b}$-e show changes compared with $\mathrm{SBS}_{\mathrm{R}}$ elastomer in the fracture surface after the addition of 2D nanocarbon materials. Mainly, the $\mathrm{SBS}_{\mathrm{R}} \mathrm{GO} 0.01 \mathrm{wt} \%$ nanocomposite showed the marked, notable patterns related to tearing lines, which are characteristic in fracture of elastomers. These changes are related to the response to the stress transfer from the matrix to the reinforcer [22, 23].

The geometry in 2D carbon nanomaterials plays a crucial role during the stress transfer [20, 24]. When a load is applied to the nanocomposite, the polymer matrix begins to deform around the graphenederivative sheet. The deformation origins a shear force between the polymer and the 2D nanomaterials concentrated in the vicinity of the sheet. At the point where the strain of the 2D nanomaterials and the polymer reach the same shear strain, a reinforcement effect comes from the differences in elastic modulus among the polymer and the 2D carbon nano-materials. When both are at the same strain, the stress in 2D sheets is more significant than in the matrix [20]. Also, the distortions and the resultant defects of GO result in a rough and winkled topology on the nanoscale which ensures a strong elastomerto-filler interaction [25]. Finally, the fracture surface of the nanocomposites with the best response in TS $\left(\mathrm{SBS}_{\mathrm{R}}-\mathrm{GO} 0.01 \mathrm{wt}\right.$. \% and $\mathrm{SBS}_{\mathrm{R}}-\mathrm{XG} 0.01 \mathrm{wt}$ \%) evidence not obvious agglomerated 2D graphene derivatives, which points towards the best combination between dispersion and transfer of mechanical properties from nanomaterials to elastomer. Moreover, the functional groups present in these nanomaterials points that the high state of oxidation in the GO, and the respective oxidation in the case of the XG, impacts positively on the TS. Consequently, the river-like fracture patterns exhibited on these composites confirmed what was mentioned by other authors [26, 27]. Similar to our study, a previous work reported agglomerate formation during melt-compounding when carbonaceous filler was added to $\mathrm{SBS}_{\mathrm{R}}$ triblock matrix, finding also that the amount of filler plays an important role to define its level of dispersion over the elastomeric matrix [28]. 
According to some references [29-31], the functional groups in the carbon reinforcer nanoparticles induce physical interactions between the elastomeric matrix and the nanoreinforcer; these matrixnanoparticles interactions improve the dispersion. In the other hand, chemical interactions between the carbon nanoparticles and the SBS matrix may be triggered when melt mixing process is employed [32].

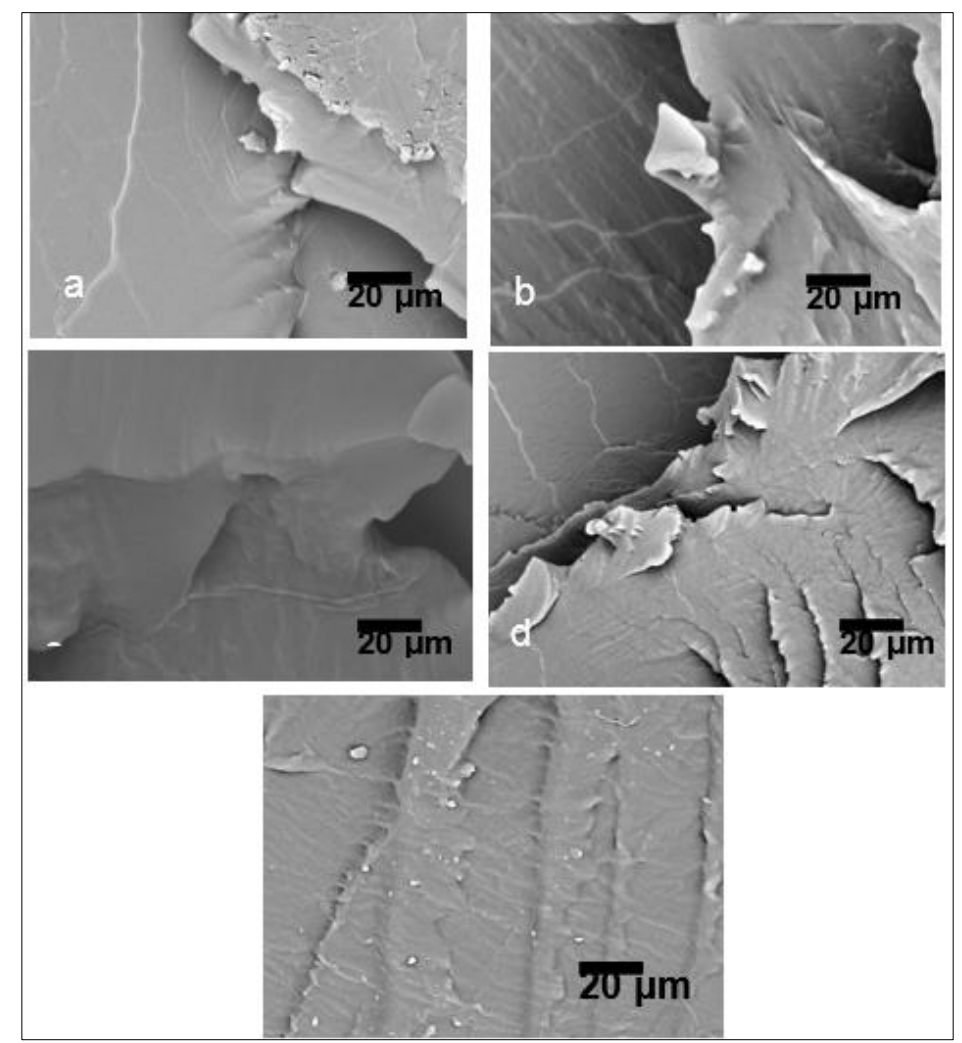

Figure 1. Fracture surface micrographs of a) $\mathrm{SBS}_{\mathrm{R}}$, of $\mathrm{SBS}_{\mathrm{R}}$ nanocomposites reinforced with b) GO 0.01 wt. \%;

c) RGO 0.01 wt. \%; d) EG 0.01 wt. \%; e) XG 0.01 wt. \%

\subsection{Thermal analysis of the $\mathrm{SBS}_{\mathrm{R}}$ and its nano-composites}

The thermal behavior of the nanocomposites was evaluated in order to analyze the influence of the addition of different nanomaterials into the elastomeric matrix. All composites exhibit a single step thermal decomposition from 350 to $450^{\circ} \mathrm{C}$, attributed to the decomposition of the elastomeric matrix backbone [28]. Since all the composites behave similarly, making hard to identify significative changes, the first derivative of the loss weight was plotted. Figure 2 (left)-(right) depicts the DTG curves for the nanocomposites and SBS, from where it is observed that the degradation temperature of the composites was higher than that of the neat $\mathrm{SBS}_{\mathrm{R}}$. This observation suggests that an interaction is established between the elastomeric matrix and the carbon nanoparticles at the interface, which would decrease the mobility of the polymer chains near the interface and increase the thermal stability of the composites. Therefore, different thermal behavior resulted in the composites as different nanomaterials were added to the elastomeric matrix. Although the total content of reinforcer was fixed, the thermal stability decreased in the order $\mathrm{GO}>\mathrm{XG}>\mathrm{RGO}>\mathrm{EG}>\mathrm{SBS}_{\mathrm{R}}[5]$, at $0.01 \%$ wt in neat $\mathrm{SBS}_{\mathrm{R}}$, with a slight increase on the thermal stability $\left(4{ }^{\circ} \mathrm{C}\right)$ of the elastomeric matrix when $\mathrm{GO}$ was added to $\mathrm{SBS}_{\mathrm{R}}$.

Figure 2 right shows the enlargement of the DTG curves; the change in the thermal stability of the nanocomposites maybe caused by the fact that some amounts of reinforcer act as heat source, promoting thermal degradation. Thus, a real contribution of reinforcement into the matrix is reached.

Yuanquin et al. [6] reported the maximum thermal degradation temperature of RGO/HO-SBS $\mathrm{R}$ composites, finding that it becomes slightly lower as the RGO content increases. Other report indicates 
that the heating rate has a significative effect on the thermal stability of $\mathrm{SBS}_{\mathrm{R}}$-carbon nanotubes composites, having a negative effect which decreased the elastomeric thermal stability [33].

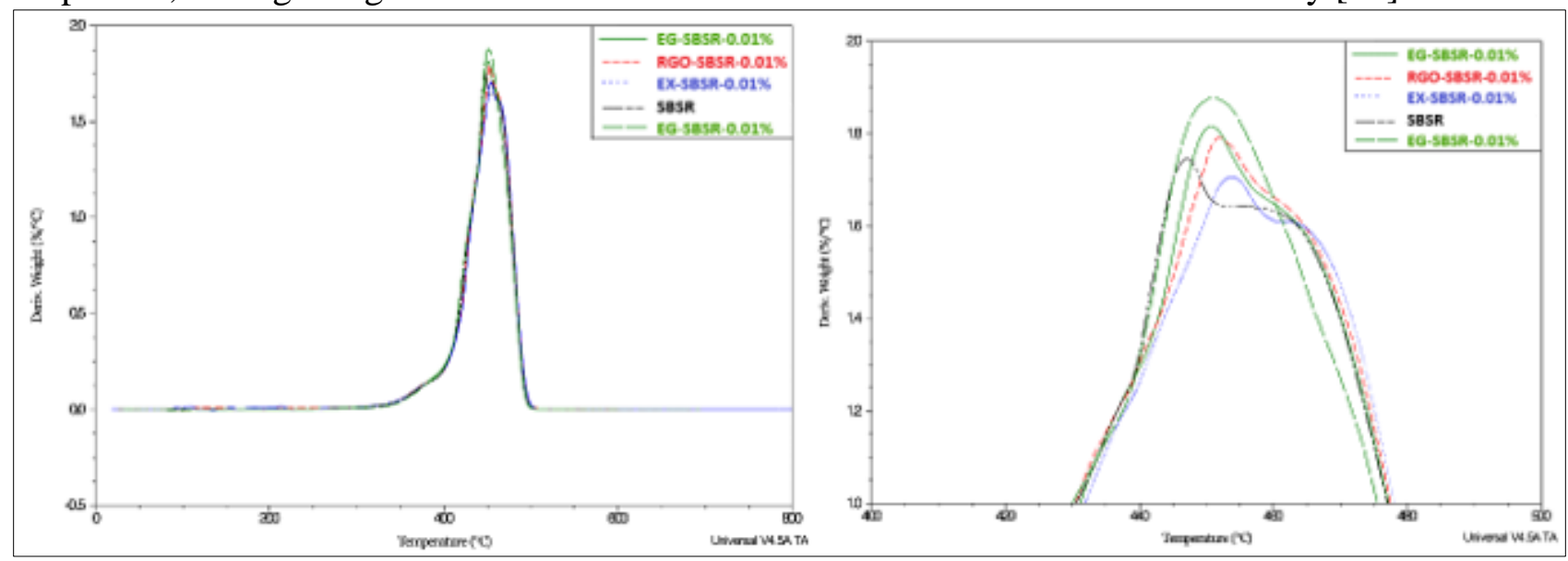

Figure 2. DTG curves of $\mathrm{SBS}_{\mathrm{R}}$ and composites at $0.01 \%$ (left), Enlargement of the DTG curves of SBS and composites at $0.01 \%$ (right)

\subsection{Dynamic Mechanical Analysis (DMA)}

The storage modulus (E') and Tan $\delta$ curves as a function of the temperature of the composites were obtained by DMA. The evaluation of these properties will be focused on the influence of adding different reinforcers into the elastomeric matrix of radial structure. By using the storage modulus curve, the glass transition temperature $(\mathrm{Tg})$ and the crosslinking density $\left(\mathrm{V}_{\mathrm{e}}\right)$ were determined and reported in Table 2. However, the analysis of the curves will only focus on the reinforced $\mathrm{SBS}_{\mathrm{R}}$ composites that showed the best storage modulus behavior.

As observed in Table 2, the crosslinking densities $\left(\mathrm{V}_{\mathrm{e}}\right)$ of all the $\mathrm{SBS}_{\mathrm{R}}$ materials suggest better matrix-reinforcer interactions as a result of having polymeric chains of star structure, which is consistent with previous studies regarding radial structure matrices [34]. Moreover, the presence of oxygenated functional groups does not interfere with the vulcanization process of the elastomeric matrix. Conversely, when GO was added, the vulcanization process was favored, as shown by $\mathrm{V}_{\mathrm{e}}$, followed by $\mathrm{RGO}>\mathrm{XG}>\mathrm{EG}$ in the case of $\mathrm{SBS}_{\mathrm{R}}$. These results can be related to the mechanical properties; first, as other authors reported $[34,35]$, the presence of the functional groups favor the dispersion. Second, the vulcanization is less affected were dispersion is appropriately acquired. For the $\mathrm{SBS}_{\mathrm{R}}$, it is possible to infer that the amount of reinforcer added was excessive, which impacted negatively on the vulcanization process. As the table 2 shows for the low concentration of $2 \mathrm{D}$ carbon in nanocomposites, the $\mathrm{V}_{\mathrm{e}}$ is almost similar to that of the elastomeric matrix. In contrast, for the high percentage of reinforcer, the $\mathrm{V}_{\mathrm{e}}$ falls considerably in all cases. However, these results need to be studied more deeply, as Stainer et al. reported [36], who found that the best performance of GO-natural rubber composites was achieved when a high amount (1 wt. \%) of 2D carbon nanomaterial was added.

Table 2. Storage modulus, $\mathrm{Tg}$, and crosslinking density of the $\mathrm{SBS}_{\mathrm{R}}$, and 2D nanocomposites

\begin{tabular}{|c|c|c|c|c|}
\hline \multirow{2}{*}{ Material } & Wt \% & Storage modulus, (MPa) & Tg, ${ }^{\mathbf{o}} \mathbf{C}$ & Crosslinking density, (V $\mathbf{e})$ \\
\hline \multirow{2}{*}{ SBS $_{\mathrm{R}}$} & 0 & 568 & -80 & 2451.59 \\
\hline \multirow{2}{*}{ SBS $\mathrm{R}-\mathrm{GO}$} & 0.01 & 644 & -81 & 3028.43 \\
\cline { 2 - 5 } & 0.1 & 551 & -79 & 3028.43 \\
\hline \multirow{2}{*}{ SBS $_{\mathrm{R}-\text { RGO }}$} & 0.01 & 408 & -80 & 2884.22 \\
\cline { 2 - 5 } & 0.1 & 372 & -80 & 2451.59 \\
\hline
\end{tabular}




\begin{tabular}{|c|c|c|c|c|}
\hline \multirow{3}{*}{ SBS $_{\mathrm{R}}-\mathbf{E G}$} & 0.01 & 551 & -82 & 1874.74 \\
\cline { 2 - 5 } & 0.1 & 684 & -79 & 2163.17 \\
\hline \multirow{3}{*}{ SBS $_{\mathrm{R}-X G}$} & 0.01 & 1032 & -77 & 2018.96 \\
\cline { 2 - 5 } & 0.1 & 379 & -83 & 2018.96 \\
\hline
\end{tabular}

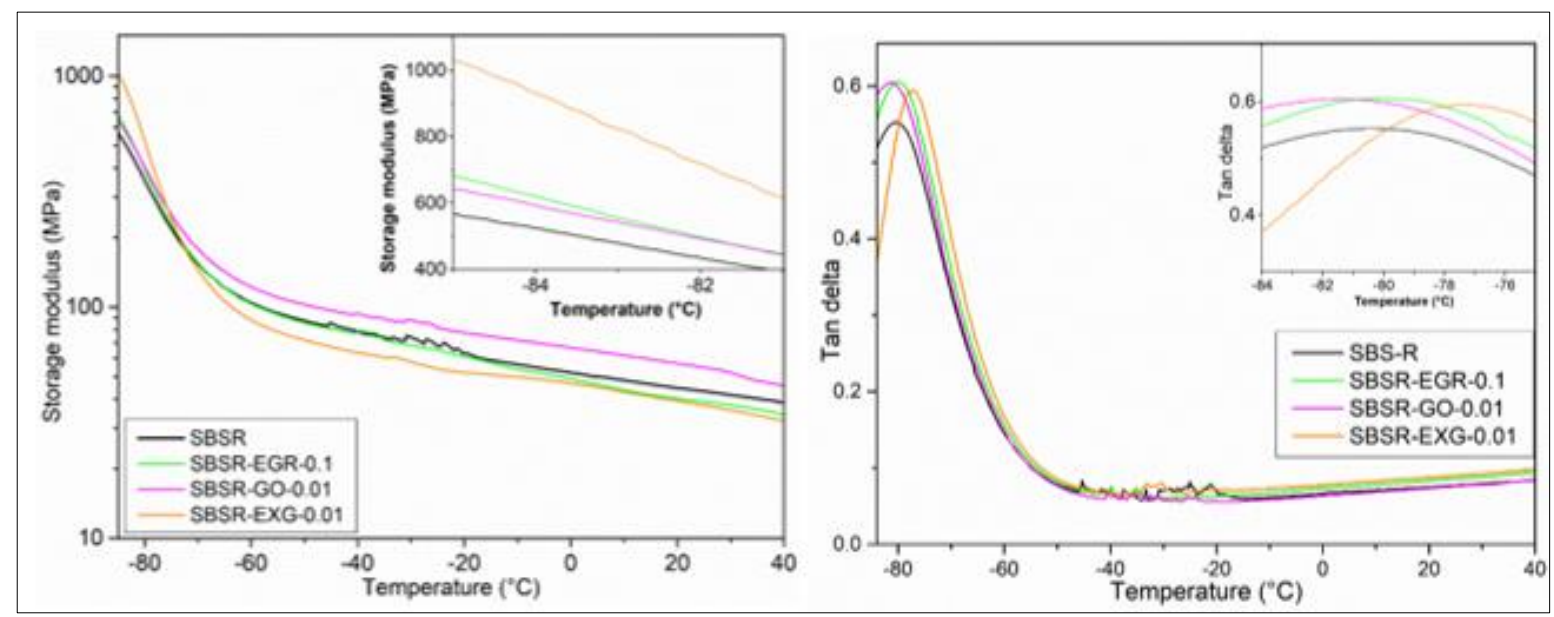

Figure 3. Storage modulus ( $\left.\mathrm{E}^{\prime}\right)(\mathrm{left})$ and $\mathrm{Tan} \delta$ (right) for $\mathrm{SBS}_{\mathrm{R}}$ and $2 \mathrm{D}$ nanocomposites

Figure 3-left shows the curves of the storage module of the nanocomposites that reached higher values of $E^{\prime}$ than the $S_{B S}$ polymer matrix. In the curves of the storage modulus, the highest value of $\mathrm{E}^{\prime}\left(-85^{\circ} \mathrm{C}\right)$ correspond to the composites reinforced with EG, GO and XG. $82 \%$ of increase with respect to $\mathrm{SBS}_{\mathrm{R}}\left(\mathrm{E}^{\prime}=568 \mathrm{MPa}\right)$ is reached using only $0.01 \mathrm{wt} \%$ of $\mathrm{XG}\left(\mathrm{SBS}_{\mathrm{R}}-\mathrm{XG}-0.01\right)$. On the other hand, increases of $13 \%$ and $20 \%$ were achieved with $0.01 \mathrm{wt} \%$ and $0.1 \mathrm{wt} \%$ of GO and EG, respectively. With respect to the increase of $13 \%$ due to the incorporation of GO, it produces great stiffness at low temperatures of the elastomer, as previously reported in a study where graphene oxide was also used to reinforce a natural rubber, and the same behavior was observed by adding this type of filler [37].

The Tan $\delta$ is determined by the ratio of loss (E') and storage (E') modulus as a function of temperature [27]. This ratio reflects the reinforcement/matrix adhesion level. In the DMA, the maximum of the $\tan \delta$ is related to $\mathrm{Tg}$. The term $\mathrm{Tg}$ is the reversible transition in amorphous materials (including amorphous regions within semi-crystalline materials) from a molten or rubber-like state into a hard and relatively brittle, glassy state [38]. Table 2 presents the values obtained for Tg, and Figure 3 (right) shows the $\tan \delta$ curves for the analyzed materials.

$\mathrm{Wu}$ et al reported that the addition of a carbonaceous filler to $\mathrm{SBS}_{\mathrm{R}}$ elastomer did not improve the storage modulus in the glassy region, but in rubbery region it had the inverse effect. This phenomenon was attributed to the intercalation of the filler in the elastomeric matrix, which affected the mobility of the polymer chains [37].

\subsection{Wide Angle X-ray Scattering}

Composites with $\mathrm{SBS}_{\mathrm{R}}$ polymer display a well-resolved diffraction peak superimposed on an amorphous background, as seen in Figure 4. The peak of maximum intensity at $2 \theta \sim 19.4^{\circ}$ is attributed to the characteristic peak of pure graphite. The diffraction patterns were similar for all $\mathrm{SBS}_{\mathrm{R}}$-graphene composites, differing only in their intensities. Small decreases probably reflect reductions in remaining intercalants. Intercalation of the thermally exfoliated graphene (EG) is expected to increase the distance between graphene sheets $[1,2,6]$. The mixing temperature plays an important role affecting the interlayer spacing in the elastomeric matrix, showing that delamitation is induced at lower temperatures [12]. 


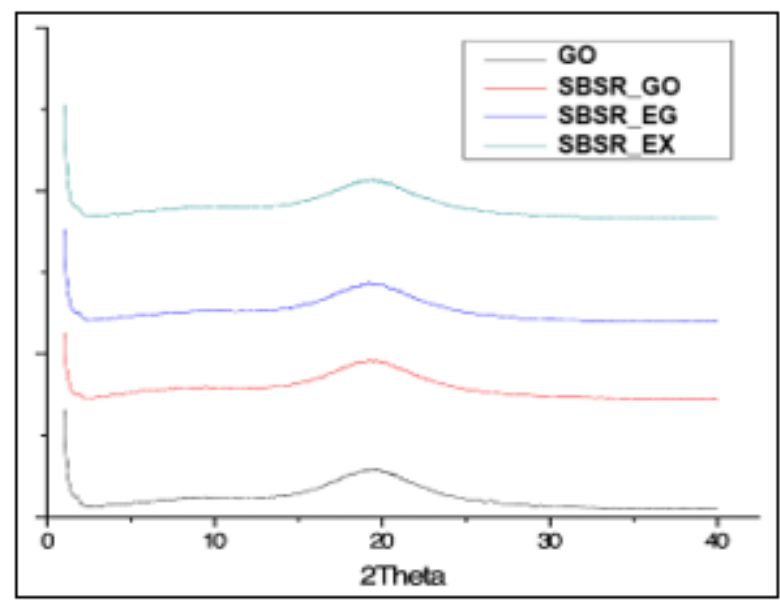

Figure 4. XRD spectra of $\mathrm{SBS}_{\mathrm{R}}$ and

$\mathrm{SBS}_{\mathrm{R}} /$ graphene composites

\section{Conclusions}

The addition of different carbon nanoreinforcers over $\mathrm{SBS}_{\mathrm{R}}$ elastomeric matrix has a variable effect on properties; GO y XG cause an increment on tensile strength (TS) attributed to a high stability of lattice built by the $\mathrm{sp}^{2}$ bonds. In general mechanical properties show an increase compared with $\mathrm{SBS}_{\mathrm{R}}$ pristine and an increasing of reinforcer load causes decrease of the stiffness of the composites. In the other hand, he addition of modified graphene particles to the nanocomposites exhibited a flake-shaped surface, and some evidence of exfoliation was found by micrographs of the fractured surface, due to the stress transfer from the elastomeric matrix to the reinforcer. Also, the geometry of carbon nanoparticles plays an important role in the stress transfer.

The thermal stability of nanocomposites was higher compared with $\mathrm{SBS}_{\mathrm{R}}$ pristine, in a decreasing order $\mathrm{GO}>\mathrm{XG}>\mathrm{RGO}>\mathrm{EG}$. The DMA helps to determine the crosslinking density of nanocomposites, obtaining that prepared nanocomposites have a good matrix-nanoreinforcer interaction attributed to lake star structure of $\mathrm{SBS}_{\mathrm{R}}$. The storage modulus of nanocomposites was higher compared with elastomeric matrix and Tg value determinate using Tan $\delta$ curve shows that there is not a significative change in this property of nanocomposites compared with pristine elastomeric matrix.

Acknowledgments: The present project financial support from Tecnológico Nacional de México, with code 6446.18-P and MAD-PYR-2019-7433. The authors are grateful to to Ph.D. Marina Vega from the CGEO-UNAM for technical support in SEM analysis, also appreciate the support of undergraduate students, Karem María Moreno Rocha, Jesus Maya Perales, Luis Isaac Naranjo Hernández, and Diego Armando Pavón.

\section{References}

1. KUILLA, T., BHADRA, S., YAO, D., KIM, N.H., BOSE, S., LEE, J.H., Recent advances in graphenbased polymer composites, Prog. Polym. Sci.,35, 2010, 1350-1375.

2.LIU, Y. T., XIE, X. M., YE, X. Y., High-concentration organic solutions of poly(styrene-co-butadieneco-styrene)-modified graphene sheets exfoliated from graphite, Carbon, 49, 2011, 3529-3537.

3.LÓPEZ-BARROSO， J., MARTÍNEZ-HERNÁNDEZ， A. L., RIVERA-ARMENTA， J. L. VELASCO-SANTOS, C., Multidimensional Nanocomposites of Epoxy Reinforced with 1D and 2D Carbon Nanostructures for Improve Fracture Resistance, Polymers, 10(3), 2018, 281-300.

4.PAPAGEORGIOU, D. G., KINLOCH, I. A., YOUNG, R. J., Graphene/elastomer nanocomposites, Carbon, 5, 2015, 460-484.

5.TAN, Q. C., SHANKS, R. A., HUI, D., KONG, D., Functionalised graphene-multiwalled carbon nanotube hybrid poly(styrene-b-butadiene-b-styrene) nanocomposites, Composites Part B: Engineering, 90, 2016, 315-325. 
6.XIONG, Y., XIE, Y., ZHANG, F., OU, E., JIANG, Z., KE, L., HU, D., XU, W., Reduced graphene oxide/hydroxylated styrene-butadiene-styrene tri-block copolymer electroconductive nanocomposites: Preparation and properties, Mater. Sci. Eng.: B, 177, 2012, 1163-1169.

7.YOUSEFI, N., LIN, X., ZHENG, Q., SHEN, X., POTHNIS, J. R., JIA, J., ZUSSMAN, E., KIM, J. K., Simultaneous in situ reduction, self-alignment and covalent bonding in graphene oxide/epoxy composites, Carbon, 59, 2013, 406-417.

8.LEE, C., WEI, X., KYSAR, J. W., HONE, J., Measurement of the Elastic Properties and Intrinsic Strength of Monolayer Graphene, Science, 321, 2018, 385-388.

9.NANDANAPALLI, K. R., MUDUSU, D., LEE, S., Functionalization of graphene layers and advancements in device applications, Carbon, 152, 2019, 954-985.

10.MANUEL, G., MOHANTY, A., Investigation of mechanical properties of graphene decorated with graphene quantum dot-reinforced epoxy nanocomposites, J Appl. Polym. Sci., 10, 2019, 468680-468692. 11.SABZEVARI, M., CREE, D. E., WILSON, L. D., Mechanical properties of graphene oxide-based composite layered materials, Mater. Chem. Phys., 234, 2019, 81-89.

12.ESTRADA-MORENO, I.A., LEYVAS-PORRAS, C., MENDOZA-DUARTE, M.E., FLORESGALLARDO, S.G., RIVERA-ARMENTA, J.L., Graphite nanoplatelets in elastomer composites, Microsc. Microanal., 25 (2), 2019, 1782-1783.

13.FIM, F.C., BASSO, N.R.S. GRAIN, A.P., AZAMBUJA, D.S., GALLAND, G.B., Thermal, electrical and mechanical properties of plyethylene-graphene nanocomposites obtained by in situ polymerization, J. Appl. Polym. Sci., 128 (5), 2012, 2630-2637.

14.TAVMAN, I., KRUPA, I., OMASTOVA, M., SARIKANAT, M., NOVAK, I., SEVER, K., OZDEMIR, I., SEKI, Y., PODHRADSKA, S., MOSKOVA, D., ERBAY, E., GUNER, F., Effects of conductive graphite filler loading on physical properties of high-density polyethylene composite, Polym. Compos., 33 (7), 32012, 1071-1076.

15.DEL PINO-PÉREZ, L.A.M., MORALES-CEPEDA, A.B., GARCÍA-ALAMILLA, R., RIVERAARMENTA, J.L., SANCHEZ-VALDÉZ, S., Nanostructures of Graphene oxide modified with ZnO: Synthesis and photocatalyst evaluation under sunlight, Fullerenes, Nanotubes Carbon Nanostruct., 2019, 27 (8), 632-639.

16.NAVARRO-PARDO, F., MARTÍNEZ-BARRERA， G., MARTÍNEZ-HERNÁNDEZ, A. L., CASTAÑO, V. M., RIVERA-ARMENTA, J. L., MEDELLÍN-RODRÍGUEZ, F., VELASCOSANTOS, C., Nylon 6,6 electrospun fibres reinforced by amino functionalised 1D and 2D carbon, IOP Conf. Series: Mater. Sci. Eng., 40, 2012, 012023.

17.DE LA LUZ-ASUNCIÓN, M., SÁNCHEZ-MENDIETA, V., MARTINEZ-HERNANDEZ, A. L., CASTAÑO, V. M., VELASCO-SANTOS, C., Adsorption of Phenol from Aqueous Solutions by Carbon Nanomaterials of One and Two Dimensions: Kinetic and Equilibrium Studies, J. Nanomater., 2015, 2015, 1-14.

18.PEREZ-RAMÍREZ, E. E., DE LA ROSA-A, G. DE LA ROSA-ÁlVAREZ, P. SALAS, P., VELASCO-SANTOS, C., MARTÍNEZ-HERNÁNDEZ, A. L., Comparison as Effective Photocatalyst or Adsorbent of Carbon Materials of One, Two, and Three Dimensions for the Removal of Reactive Red 2 in Water, Environmental Engineering Science, 32, 2015, 1-9.

19.WEN, Y., HE., ZHU, Y., HAN, F., XU, X., MATSUDA, I., ISHII, Y., CUMINGS, J., WANG, C., Nature communications, Expanded graphite as superior anode for sodium-ion batteries. Nature Communications, 5, 2014, 4033.

20. PALERMO, V., KINLOCH, I. A., LIGI, S., PUGNO, N. M., Nanoscale mechanics of graphene and graphene oxide in composites: A scientific and technological perspective, Adv. Mater., 2016, 28, 62326238.

21.YOUNG, R. J., KINLOCH, I. A., GONG, L., NOVOSELOV, K.S., The mechanics of graphene nanocomposites: A review, Compos. Sci. Techn., 72, 2012, 1459-1476.

22.GENT, A. N., PULFORD, C. T. R., Micromechanics of fracture in elastomers, J. Mater. Sci., 19, 1984, 3612-3619. 
23.LE CAM, J.-B., HUNEAU, B., VERRON, E., Failure analysis of carbon black filed styrene butadiene rubber under fatigue loading conditions, Plast. Rubber Compos., 43,2014, 187-191.

24.YOUNG, R. J., LIU, M., KINLOCH, I. A., LI, S., ZHAO, X., VALLES, C., PAPAGEORGIOU, D. S., The mechanics of reinforcement of polymers by graphene nanoplatelets, Compos. Sci. Tech., 154, 2018, 110-116.

25.WU, X., LIN, T. F., TANG, Z. H., GUO, B.C., HUANG, B. S., Natural rubber/graphene oxide composites: Effect of sheet size on mechanical properties and strain induced crystallization behavior, Exp. Polym. Lett., 9, 2015, 672-685.

26.REN, Q., CHEN, J., CHU, F., LI, J., YU, Q., WU, D., FANG, J., Graphene/star polymer nanocoating, Prog. Org. Coat., 103, 2017, 15-22.

27.LI, Z., YOUNG, R. J., WANG, R., YANG, F., HAO, L., JIAO, W., LIU, W., The role of functional groups on graphene oxide in epoxy nanocomposites, Polym., 54, 2013, 5821-5829.

28.WU, H., THAKUR, V.K. \& KESSLER, M.R. Novel low-cost hybrid composites from asphaltene/SBS tri-block copolymer with improved thermal and mechanical properties. J. Mater. Sci., 51, 2016, 2394-2403.

29.IBARRA, L., PAÑOS, D., Dynamic properties of thermoplastic butadiene-styrene (SBS) and oxidized short carbon fiber composite materials, J. Appl. Poly. Sci., 67, 1998, 1819-1826.

30.LU, L., ZHOU, Z., ZHANG, Y., WANG, S., ZHANG, Y., Reinforcement of styrene-butadienestyrene tri-block copolymer by multi-walled carbon nanotubes via mewl mixing, Carbon, 45, 2007, 2621-2627.

31.MARINHO, T., COSTA, P., LIZUNDIA, E., COSTA, C.M., CORONA-GALVÁN, S., LANCEROS-MÉNDEZ, S., Ceramic nanoparticles and carbon nanotubes reinforced thermoplastic materials for piezocapacitive sensing applications, Compos. Sci. Tech., 183, 2019, 107804.

32.COSTA, P., SILVA, J., ANSÓN-CASAOS, A., MARTINEZ, M.T., ABAD, M.J., VIANA, J., LANCEROS-MENDEZ, S., Effect of carbon nanotube type and functionalization on the electrical, thermal, mechanical and electromechanical properties of carbon nanotube/styrene-butadiene-styrene composites for large strain sensor applications, Compos.: Part B, 61, 2014, 136-146.

33.LU, L., YU, H., WANG, S., ZHANG, Y., thermal degradation behavior of styrene-butadiene-styrene tori-block copolymer/multiwalled carbon nanotubes composites, J. Appl. Polym. Sci., 112, 2009, 524531.

34.XUE, X., YIN, Q., JIA, H., ZHANG, X., WEN, Y., JI, Q., XU, Z., Enhancing mechanical and thermal properties of styrene-butadiene rubber/carboxylated acrylonitrile butadiene rubber blend by the usage of graphene oxide with diverse oxidation degrees, Appl. Surf. Sci., 243, 2017, 584-591.

35.LI, Z., YOUNG, R. J., WANG, R., YANG, F., HAO, L., JIAO, W., LIU, W., The role of functional groups on graphene oxide in epoxy nanocomposites, Polym., 54, 2013, 5821-5829.

36.STANIER, D. C., PATIL, A. J., SRIWONG, C., RAHATEKAR, S., CIAMBELlA, J., The reinforcement effect of exfoliated graphene oxide nanoplatelets on the mechanical and viscoelastic properties of natural rubber, Compos. Sci. Technol., 95, 2014, 59-66.

37. TANG, L. C., WAN, Y. J., YAMG, D., PEI, Y. B., ZHAO, L., LI, Y. B., WU, L. B., JIANG, J. X., LAI, G. Q., The effect of graphene dispersion on the mechanical properties of graphene/epoxy composites, Carbon, 60, 2013, 16-27.

38. FLORES-HERNANDEZ, C. G., COLIN-CRUZ, A., VELASCO-SANTOS, C., CASTAÑO, V. M., ALMENDAREZ-CAMARILLO, A., OLIVAS-ARMENDARIZ, I., MARTINEZ-HERNANDEZ, A. L., Chitosan-Starch-Keratin Composites: Improving ThermoMechanical and Degradation Properties Through Chemical, J. Polym. Environ., 26, 2018, 2182-2191.

$\overline{\text { Manuscript received: } 27.05 .2020}$ 